\title{
The BETA $^{\circledR}$ nursing measure: Its development and testing for nursing utility
}

\begin{abstract}
Authors:
Hendrik J. Loubser ${ }^{1}$

Judith C. Bruce ${ }^{2}$

Daleen Casteleijn ${ }^{3}$

Affiliations:

${ }^{1}$ South African Database for

Functional Medicine,

South Africa

${ }^{2} \mathrm{School}$ of Therapeutic Sciences, University of the

Witwatersrand, South Africa

${ }^{3}$ Department of Occupational Therapy, University of the

Witwatersrand, South Africa
\end{abstract}

\section{Correspondence to:}

Hendrik Loubser

Email:

hennie@sadfm.co.za

Postal address:

PO Box 2356, Houghton

2041, South Africa

\section{Dates:}

Received: 21 Sept. 2012

Accepted: 15 May 2013

Published: 30 Aug. 2013

Republished: 27 Nov. 2013

How to cite this article: Loubser, H.J., Bruce, J.C. \& Casteleijn, D., 2013, 'The BETA $^{\circledR}$ nursing measure: Its development and testing for nursing utility', Health SA Gesondheid 18(1), Art. \#697, 9 pages. http://dx.doi. org/10.4102/hsag.v18i1.697

\section{Note:}

This article was republished with the corrected title.

\section{Copyright:}

(C) 2013. The Authors. Licensee: AOSIS

OpenJournals. This work is licensed under the Creative Commons Attribution License.
In the specialised nursing fields of rehabilitation, convalescence and gerontology requiring restorative nursing interventions, nurses are unable to measure, assess and evaluate accurately and routinely the outcomes of their patients' activities of daily living (ADLs) due to the lack of validated nursing measures. The purpose of this study was to develop a nursing scale, named the BETA, which can be used routinely and embedded into the nursing process and care plan, enabling the primary nursing carer to measure, assess and evaluate patients' ADLs. The first objective was to design and develop the BETA, a routine nursing scale, whereby caregivers and nursing auxiliaries can observe, score and record their patients' activities of daily living. The second objective was to test the BETA's nursing utility to be used routinely. Two qualitative studies were done sequentially. Firstly, individual interviews were conducted to collect descriptive data from registered nurses $(n=6)$, nursing assistants, $(n=8)$ and caregivers $(n=16)$, skilled in the field of restorative care. In the first study, the data were analysed using inductive content analysis techniques to design and construct the BETA nursing measure. In the second study, the BETA's nursing utility was studied by means of the training of and testing the application of the BETA by a new team of professional nurses $(n=6)$ and caregivers $(n=48)$ working in a geriatric frail care unit. After 6 months, two homogenous focus groups consisting of registered nurses $(n=3)$ and caregivers $(n=5)$ representing this team were interviewed to explore the BETA's nursing utility. Descriptive data in the second study were analysed using deductive content analysis. The initial results were promising. The high levels of agreement on its acceptance, usefulness and confidence, to be used routinely as a nursing scale, confirmed the BETA's nursing utility. The BETA nursing scale has the potential to introduce restorative nursing as a new specialisation field in South African nursing, a much needed service required by patients and multidisciplinary teams. This, however, will depend on the construct validity of the BETA, a study to be reported on in a follow-up article.

Gespesialiseerde verpleging vir rehabilitasie, herstelling en gerontologie benodig restoratiewe intervensies, maar verpleegsters kan nie die uitkomste van hul pasiënte se aktiwiteite van daaglikse lewe (ADLs) akkuraat en geroetineerd meet, assesseer en evalueer nie, asgevolg van 'n gebrek aan geldige meet instrumente. Die doel van hierdie studie was om die BETA, 'n verplegings meet skaal, te ontwikkel wat roetineweg deel kan word van die verplegingsproses en sorgplan en wat die primêre versorger in staat stel om pasiënte se ADLs te meet, assesseer en evalueer. Die eerste doelwitte was om die BETA skaal te ontwerp en ontwikkel vir primêre versorgers om hul pasiënte se ADLs roetineweg te kan waarneem en opteken. Die tweede doelwit was om die BETA skaal se nuttigheid vir verpleegsters te toets. Daar is twee opeenvolgende kwalitatiewe studies gedoen. Eers is daar individuele onderhoude gevoer om beskrywende data te versamel van geregistreerde verpleegsters $(n=6)$, verpleegassistente, $(n=8)$ en versorgers $(n=16)$, wat bedrewe is in die veld van restoratiewe verpleging. In die eerste studie is die data geanaliseer met behulp van induktiewe inhoudsanalisetegnieke om die BETA skaal te ontwerp en op te stel. In die tweede studie is die BETA se nuttigheid vir verpleging bestudeer deur opleiding en toetsing in die toepassing van die BETA deur'n nuwe span geregistreerde verpleegsters $(n=6)$ en versorgers $(n=48)$ wat in 'n versorgingseenheid vir geriatriese verswaktes werk. Na ses maande is twee homogene fokusgroepe gehou, bestaande uit geregistreerde verpleërs $(n=3)$ en versorgers $(n=5)$ wat hierdie span verteenwoordig, om die nuttigheid vir verpleging te ondersoek. Beskrywende data in die tweede studie is met behulp van deduktiewe inhoudsanalisetegnieke geanaliseer. Die aanvanklike resultate was belowend. Die BETA se nuttigheidsvlakke vir verpleging het hoë hoogtes van aanvaarding, betroubaarheid en vertroue bevestig. Die BETA-verplegingskaal het die potensiaal om restoratiewe verpleging as 'n nuwe spesialiseringsveld in Suid-Afrikaanse verpleging te bewerkstellig, $n$ baie nodige diens vir beide pasiënte en multidissiplinêre spanne. Dit sal egter afhang van die geldigheid van die BETA, 'n studie waaroor daar in 'n opvolgartikel verslag gedoen sal word. 


\section{Introduction}

The consequences of trauma and chronic illness may be impairment, disability or handicap (World Health Organization 1980) and the key for nurses to understand the extent of these consequences is to document the activities of daily living (ADLs) accurately and routinely (LundgrenNilsson 2006). However, measuring ADLs is a complex task and there is a paucity of such measures in the nursing sciences. The gold standard of ADL measurement in USA rehabilitation facilities is the Functional Independent Measurement (FIM) (Nilsson, Sunnerhagen \& Grimby 2005). The FIM is an objective scoring system, designed in the 1980s by a multidisciplinary team, whereby patients' ADLs are observed and given a score within a structural framework. It is used by rehabilitation 'clinicians', a speciality accreditation not available in South Africa. None the less, rehabilitation clinicians, whether physicians, professional nurses or therapists, are not best placed to routinely observe rehabilitation patients performing their ADLs (e.g. eating, grooming, bathing, dressing). The FIM thus has an inherent structural defect as it is designed for clinicians who require valid observations on patient ability that can only be observed routinely by the nursing auxiliaries and caregivers who have to serve as a proxy rater to the clinicians. Although the FIM received extensive positive and negative reviews from clinicians, very little was reported on the FIM's usefulness and applicability to the nursing sciences (e.g. its nursing utility) and little is known on how well, if at all, the nursing profession has embraced the FIM as a routine nursing measure. The South African nursing experience will be discussed below.

\section{Background}

Over time, academics in rehabilitation and geriatric nursing have come to the conclusion that accurate ADL measurements can be particularly useful in calculating the number of nursing staff required to ensure quality care (McGillis-Hall et al. 2001). The burden of nursing care would equate to the patient's degree of disability, which can be calculated from the ADL measurements. The measurement of ADLs thus becomes a promising rationale to calculate nurse staffing whereever restorative nursing care is required, such as rehabilitation, convalescence, gerontology and longterm disability care (Heinemann et al. 1997). Furthermore, the availability of routine functional data would also assist in moving away from the traditional use of negative staffing indicators (e.g. deaths, comorbidities, complications) toward a more positive focus on staffing that is appropriate for measurable patient-evidence outcomes (Lang et al. 2004).

\section{Trends}

As nurse staffing needs are the main consideration in rehabilitation services, Nelson et al. (2007) published a study providing significant insights into the nurse's needs with regard to the daily scoring of ADLs. However, it is the collateral information provided by Nelson et al. (2007) on the FIM nursing utility that is of interest to this study. As the FIM rating scale has been the mandated ADL scale in the USA since 2002, Nelson and coworkers assumed that rehabilitation nurses would provide the daily FIM data that the researchers required in order to develop a prospective staffing model based on the patients' functional outcomes. This did not turn out to be the case.

The Nelson et al. (2007) study set out to ask nurses to collect FIM data daily, for 30 consecutive days, on all their rehabilitation patients so as to calculate the link between patient functionality and the required burden of nursing care. From 806 rehabilitation facilities in the USA, a representative sample of 235 rehabilitation facilities were selected to participate in the study. Of these, only 54 facilities' nursing management agreed to participate; the remainder declined as it was thought to place too high a burden on their nursing staff to do daily FIM scoring. Furthermore, notwithstanding the nurses' previous FIM credentials, Nelson's research team felt that the participating nurses would require retraining and re-accreditation in order for them to provide accurate FIM data. In spite of all the endeavours above, an average of $9.48 \%$ of the FIM data were recorded missing daily across all facilities, indicating a high level of nursing non-compliance with regard to using the FIM as a routine measure.

The cumulative evidence on the FIM's nursing utility is that nurses, however well-intended and -committed, could not maintain the daily effort required to observe and record the functional changes of each patient. Although nurses agree that the FIM data should render vital information for the restorative nursing process, the collateral evidence in Nelson's study indicated that the nursing process and the FIM were not compatible; either the nurses fail the FIM or the FIM fails the nursing utility.

The experience was the same in South Africa, where FIM was introduced in the late 1990s. More than 1000 registered nurses (RNs) working within multidisciplinary teams in 84 subacute facilities were trained, tested and accredited. The aim was to introduce the FIM as a routine nursing tool, but the results were disappointing. South African nurses found the FIM to have no nursing utility and would therefore not participate as part of the multidisciplinary team to produce FIM scores routinely. The following basic concerns emerged which prevented their implementation of the FIM:

- The caregivers (CGs) and nursing auxiliaries, not the RNs, are in the best position for routine observation, scoring and recording of patient ADLs. However, the FIM framework of observation, which is a registered product, was not designed to be useful at this level of direct caregiving but rather to be used for periodic assessments by multidisciplinary teams. The nurses are not familiar with the therapeutic language and concepts used in the FIM and thus cannot apply the FIM as a routine nursing score.

- Also, rendering assistance with ADLs is not a primary RN function; it is the primary function of the nursing auxiliaries or, in most instances, the caregivers. The RN 
supervises and manages the process. This is in agreement with Resnick, Cayo and Pretzer-Aboff (2009) who reported that nursing assistants and caregivers in the USA nursing facilities provide up to $90 \%$ of the direct care and functional assistance to patients. Since 1987, it has been mandatory in the USA to train long-term care nurses in restorative nursing practices. The FIM, however, is not seen as being useful to them.

These concerns made it clear that the FIM is considered to be a cumbersome and inappropriate addition to the nursing process. If forced to implement the FIM, nurses would not accept accountability for the quality of the data.

The cumulative negative experience of the FIM by South African nurses was significant. As nurses have no measures to express the outcome of the restorative nursing care rendered, they found themselves excluded from multidisciplinary meetings on patient outcomes. The restorative nursing process thus remains an unquantifiable science as it cannot provide empirical evidence of its outcomes.

\section{Purpose and objectives}

The purpose was to provide nursing auxiliaries (NAs) and CGs in a restorative care context with an objective measure of patients' ADLs, called the BETA scale. The name BETA refers to the second letter in the Greek alphabet and is the second in a suite of nursing measures currently under construction. Two objectives were identified:

- To design and develop the BETA as a nursing scale for NAs and CGs to observe, score and record their patients' ADLs, seeing as they already perform these activities daily as an integral part of the restorative nursing process.

- To test if the BETA has nursing utility, that is to say, whether the BETA is useful and acceptable enough to be embedded into the nursing process and care plans.

\section{Significance}

Restorative nursing activities are carried out primarily by NAs and CGs who support patients routinely with their ADLs. These carers are therefore best placed to observe, score and record ADL changes as they occur (Resnick 2004). Registered nurses (RNs) and therapists are characteristically not directly involved with patients and therefore not suitable to carry out these observations. However, there is no existing format or framework for CGs and NAs with regard to observation and scoring of patients' ADLs, meaning that nurses have no empirical record of patient functionality on which to base their nursing assessment. Furthermore, nurses have no routine longitudinal data on patient restorative outcomes. This study aims to resolve this paucity.

\section{Definition of key concepts}

\section{Restorative nursing}

In 1967, Sr Verah McIver created an ability-enhancing nursing model through training programmes for NAs and management and supervision programmes for the registered nurses in charge. She called it the Restorative Nursing Care Model. Today it is defined it as an enabling nursing process aimed at promoting physical and personal independence so as to restore the dignity and wholeness of the patient or disabled person (Mantle \& Funke-Furber 2003).

\section{Nursing utility}

The clinical utility of an instrument is the degree of conviction the users have about its usefulness in their professional practice (Toomey, Nicholson \& Carswell 1995), taking into consideration application practicalities such as relevance, suitability, feasibility, accuracy, comprehensiveness, credibility, flexibility, value and adaptability (Barbara \& Whiteford 2005). As this study concerns itself with the professional practice of nursing, the term 'nursing utility' has been used to describe this (Loubser 2012).

\section{Scale versus measure}

In general, the terms 'scale', 'instrument', 'test', 'tool' and 'questionnaire' may all refer to the concept of producing numerical scores in order to explain a phenomenon at an ordinal level (Bond \& Fox 2007). However, during the design and development of an instrument, as in this study, it should be referred to as a scale as it is ordinal in nature. Following a successful construct validation conversion, the scale's ordinal characteristics are transformed into one with linear interval qualities. At his point, it must be referred to as a measure (Loubser 2012; Stevens 1946).

\section{Registered nurse}

A registered nurse $(\mathrm{RN})$ is a professional who has completed a four-year academic programme in nursing or a two-year bridging programme at an accredited Nursing Education Institution (NEI) and who is registered with the South African Nursing Council as a nurse and midwife, with a speciality in either general nursing or psychiatric nursing.

\section{Nursing auxiliary (also known as a nursing assistant)}

A nursing auxiliary (NA) is a person who has completed a one-year academic programme at an approved nursing school and who is enrolled with the South African Nursing Council as a nursing auxiliary.

\section{Caregiver (also known as a care worker)}

A caregiver (CG) is not a qualified nurse and is therefore not regulated as such. However, in the non-acute nursing environment, they are an essential resource for the implementation of nursing care plans.

\section{Research design and method}

The two objectives required two studies to be executed sequentially and each study will be described separately below.

\section{First study: Development of the BETA Research design}

According to Foxcroft et al. (2004), the use of a panel of nursing experts to be involved in the design, development and review 
of instruments for nursing utility specifications, significantly contributes to the content validity of the instruments. For this reason a qualitative, exploratory design was followed in the development of the BETA. Qualitative research was best suited with regard to seeking an understanding of the actions and processes within the specific context of rehabilitative nursing and explicitly at the interface between the patients and the NAs or CGs. Exploratory research actively examines this interface as the specific phenomenon of interest rather than merely observing and reporting (Lobelo 2004:20).

\section{Sample}

The sample included RNs $(n=6)$, NAs $(n=8)$ and CGs ( $n=16)$, who had more than 2 years' experience in rehabilitation practices. The RNs, NAs and CGs were selected purposively as they each represented a different subacute facility $(n=5)$ which had previously been trained in the application of the FIM. Selection criteria included a previous knowledge of the FIM, a 6-month implementation period and a history of constructive objections as to why the FIM was not implementable as a nursing measure. The criteria also included a willingness to participate in the study and to make the NAs and CGs in their teams available for this research.

\section{Data collection}

Unstructured individual interviews were held with each of the RNs to explore why they experienced difficulty with implementing the FIM as a nursing scale. The discussions were open but focused with the objective being to explore their perceptions of why the FIM does not comply with the nursing sciences. The central question was asked: 'Why does the FIM fail as a nursing scale?' and this was then followed up with probing questions. Field notes were taken.

From the outset there was consensus amongst the participants that the final product must satisfy the following four objectives:

- The BETA must be useful at the nurse-patient interface.

- The BETA scores must facilitate a uniform language in restorative nursing.

- The BETA instrument must improve the quality of restorative nursing services.

- The BETA must fit into the nursing process and care plans.

Individual unstructured interviews continued with the RNs, always verifying that the four objectives were still intact, until data saturation was achieved.

\section{Data analysis}

The data analysis followed an inductive content analysis technique designed to transform the basic ADL constructs of the FIM, an instrument that was imbedded in the therapeutic sciences, to the BETA, an instrument that could become imbedded in the nursing sciences. The four objectives were used as the criteria for complying with the characteristics of a nursing sciences measure. The first draft on the transformation was done by the researcher and circulated to the participants for editing, deleting and adding. The respondents included their CGs and NAs in the editing process. The returned data were used by the researcher to refine the second version of the BETA. This developmental process repeated itself until version five of the BETA was concluded with no further comments from the respondents. The BETA training manual was drafted by the researcher for training, testing and accreditation of future users. Figure 1 is an example of how the decision tree was developed in order to arrive at an appropriate score.

To report on patient outcomes the respondents agreed to use the radar graph (Figure 2) in the BETA in the same way it is used in the FIM. This was done for two reasons: (1) the nursing tool had to maintain the same language as used by the therapists and (2) the radar graph, first used by Georg von Mayr in 1877, is still the best method to display the performance metrics of any ongoing programme.

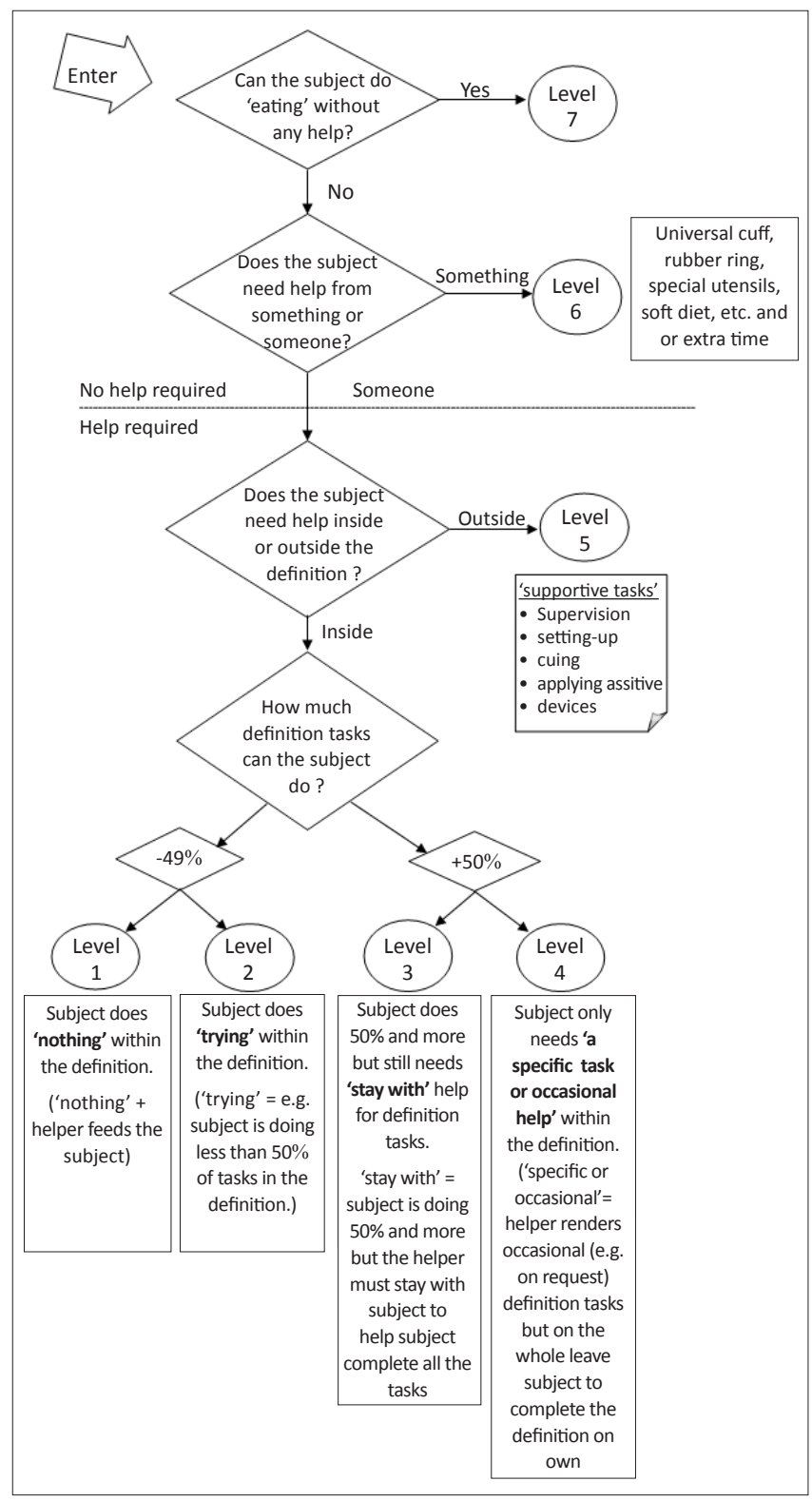

Source: Authors' own construction

FIGURE 1: The Eating item of the BETA nursing score. 


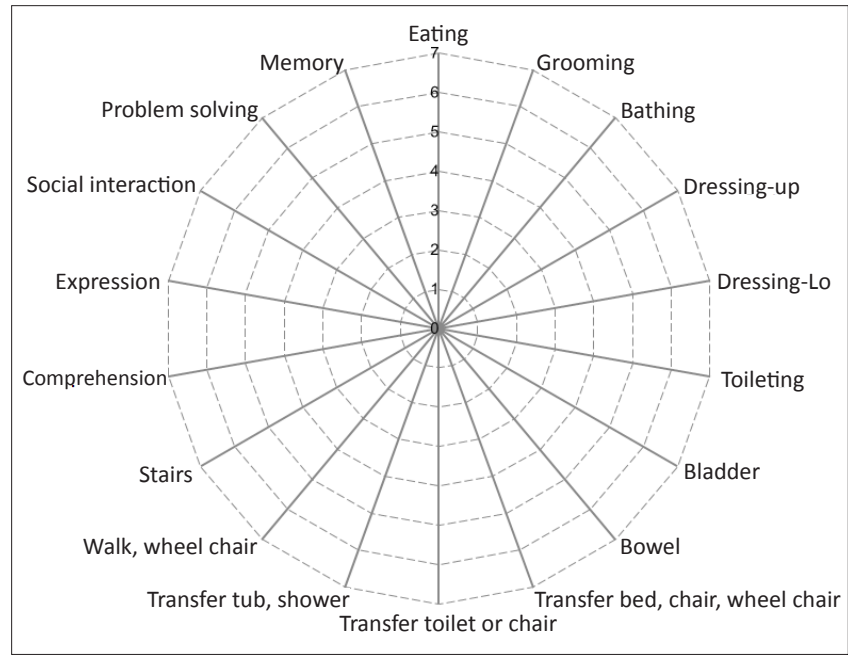

Source: Authors' own construction

FIM, Functional Independent Measurement.

FIGURE 2: Radar graph representing the BETA scale structure, based on the FIM platform.

During the training sessions, the NAs and CGs were invited to verify the appropriateness of the terminology contained in the BETA scale, as well as questioning its practical implications on their scope of work. They were asked if it was a true reflection of what was happening at the interface between the patient and their NAs and CGs when addressing ADLs. The researcher observed and recorded their responses, mannerisms, non-verbal responses, gradations and distinctions to update the primary carers' saturation with the BETA scale's first draft.

The first result was very positive in terms of the NAs' and CGs' participation. They made numerous valuable changes and suggestions, indicating that the RNs who originally participated in the design and development of the BETA were not fully aware of the depth, detail and nuances contained in the primary carer's scope of work. Indeed, the evidence of these primary carers' depth of knowledge, intuitive awareness and insight took the RNs by surprise.

The interaction between the researcher and the primary carers continued for a few months. As they started to implement the scale, new observations brought new clarity and realities to the fore, allowing the researcher to tweak the BETA scale to greater levels of accuracy. They brought various new insights that evolved into a new language and required meaningful adjustments. Each set of adjustments required a new version to be approved by all RNs, NAs and CGs. This process continued until the final version of the BETA scale was completed and all participants were in agreement that the information that could be gained from the primary carers was saturated. From this point onwards the first set of data was collected using the BETA scale.

\section{Second study: Validating nursing utility Research design}

A qualitative, exploratory and descriptive design was used to validate the nursing utility of the BETA scale. A qualitative approach was needed in order to collect narrative data as nurses described their experience regarding implementation of the BETA over a period of six months. The exploratory nature of the research gave nurses the opportunity to describe their experience in focus groups, as well as helping the researcher to gain a deeper understanding of if, how and where the BETA changed their work experience.

\section{Population and sample}

To prevent bias when testing nursing utility, a new nursing and caregiver population was required that had no previous knowledge or experience of the BETA. For this purpose, a 45-bed geriatric frail-care facility was selected. All of the permanent nursing staff ( $\mathrm{RNs}=6, \mathrm{NAs}=6$ ) and the permanent caregivers $(C G s=39)$ were trained and tested in order to become proficient in the application of the BETA. No exclusion criteria were used. To prepare them for the nursing utility study, the NAs and CGs were asked to 'score-on-thego' all the residents allocated to them every day, meaning they had to observe the residents performing their daily ADLs and record a score for each activity as they observed it being performed (e.g. eating, dressing, bathing, ablutions) and record it as a hard copy.

Six months after implementation, two focus group discussions were scheduled a month in advance to explore the different aspects of the nursing utility experienced. Purposive sampling was used to select two focus groups. The first group consisted of RNs $(n=3)$ in order to explore the value that the BETA scale added to the nursing process and care plans, as well as its effect on nursing quality. The second group consisted of CGs $(n=5)$ in order to explore the ease of integrating the BETA scale into nursing care plans and the perceived usefulness of the BETA within the primary carer's scope of work. The nurses on duty on the scheduled day of the focus group were invited to participate. Staff availability on the scheduled day limited the size of the groups.

\section{Data collection}

The focus groups followed a semi-structured approach, with four basic questions that followed the four objectives in the development of the BETA. No reading or writing was required and mannerisms and non-verbal behaviour were observed and recorded. Statements or comments could be clarified if misunderstood. Both focus group interviews were recorded and transcribed.

\section{Data analysis}

Following the good outcome from the first study, a good outcome was also anticipated for the second study. For this reason, a deductive content analysis technique of the descriptive data was applied. The four objectives posed were used to provide a predetermined framework for a coding scheme for analysis of the descriptive data. In other words, the original four objectives posed to the $\mathrm{RN}$ collaborators during the design and development were anchored as the categories used in the analysis (Hsieh \& Shannon 2005). 


\section{Ethical considerations}

This study on the BETA was approved by the Research Ethics Committee (Medical) of the University of the Witwatersrand and an ethical clearance certificate, M 10524, was obtained in May 2010. Written approval was obtained from the clinical managers of the facilities involved. The study purpose was explained to the participants before collecting data and they then gave written informed consent to participate in this study on a voluntary basis. Participants could exercise their right to withdraw from the study at any time without penalty or prejudice. The researcher also ensured anonymity and privacy and the protection of participants against discomfort or harm, be it physical, emotional, spiritual, economic, social or legal.

\section{Trustworthiness}

The four criteria of trustworthiness, namely credibility, dependability, conformability and transferability, were followed. Credibility was achieved by prolonged engagement with the participating nurses, allowing enough time during the interview for them to verbalise their perceptions regarding both the development and nursing utility studies of the BETA. Dependability was achieved through a detailed description of the research methods, peer review and triangulation of sources, namely empirical data and a literature control process, during the data analysis stage. Conformability was achieved through a detailed description of the research process, as well as during data collection through unstructured individual interviews where audio recordings were used and detailed field notes were written. Transferability was achieved through the purposive selection of the sample, as well as through a dense description of the research methods and results of the study, so that researchers who are interested in conducting similar research could gather enough information.

\section{Results}

The codes for the analyses were anchored in the four original objectives set down for development of the BETA scale. The categories were therefore: (1) the BETA is a useful nursing tool at the patient-carer interface; (2) the BETA scores facilitate a uniform language for restorative nursing; (3) the BETA improved the quality of restorative nursing services; and (4) the BETA fitted into the nursing process and care plans.

In an attempt to convey the richness of the data as expressed in the language used by the participants in the two groups, any direct quotations used (indicated in italics) came from the spokesperson of the RN or CG group when expressing an experience or opinion.

\section{Results from the Registered Nurse focus group}

There was evidence that the BETA is a useful tool at the patient-carer interface because it acts as a care plan which guides nurses and CGs into a new understanding of restorative nursing. As nurses and CGs use the BETA framework to observe their patient's functioning, they develop new insights into patient functioning and begin to know exactly what their patients' abilities are and what is required from the nurses to improve on these. Furthermore, the daily scores are recorded and serve as documented communication between shifts and are discussed at handovers. Previously, the NAs and CGs were very task orientated, doing all of the activities for the patients, but when scoring with the BETA scale, NAs and CGs became aware that the patients were capable of doing many of the tasks themselves. The BETA decision tree also guide the NAs and CGs to the next scoring level, resulting in the NAs and CGs challenging the patients to achieve a higher scoring level. The outcome is that the NAs, CGs and patients motivate one another toward the achievement of higher levels of independence, resulting in increased BETA scores. Furthermore, increasing the patients' BETA scores has now become a commodity representing a personal achievement for both the NAs and CGs. The BETA thus motivates the NAs and CGs to increase patient independence. If the scores did not improve, the NAs and CGs consulted the RNs regarding techniques to improve the scores and hence, patient outcomes. The view of the RNs was that the routine BETA scoring is a very big help in improving patient functional outcomes.

The nursing management at the facility instructed the NAs and CGs to observe and score their patients daily on hard copy whereafter the weekly score sheets were submitted for electronic data capturing. The RN discussed the changes in the patient score sheets with the NAs and CGs on a daily basis. For instance, if the patient had not had a bowel action for the day the 'bowel management' score for the day would not have been completed. The 'omissions and changes in scores form a very good discussion' around the care plans between the RNs and the NAs and CGs.

The RNs established that, as patient ADLs are within the scope of work of the NAs and CGs, the BETA scoring method is fast becoming second nature to them. The NAs and CGs can observe the functional ability of a patient with ease and can recognise change as it occurs. In fact, they are more aware than the RNs of how the patients function. With the NAs' and CGs' new-found perspective on restoring patient independence, the 'overall quality of nursing has definitely improved'. There is very strong quantifiable evidence that the patients' (frailaged persons) scores have improved substantially since the implementation of the BETA, indicating improvement in patient independence. These changes relate to quality-oflife improvements which indicate patient-evidence-based quality of nursing.

A noticeable amount of assertiveness, accountability and increased motivation was observed amongst the NAs and CGs. The result is that CGs are able to be taken out of the housekeeping team and integrated into the nursing care team. 
They have become enthusiastic about their new role and it has become a morale boost to them. They now participate in the nursing discussions and find the new language easy to manage in terms of expressing themselves by means of scores when discussing patient functionality. They understand their task as that of implementing a nursing procedure and they do it with the required discipline, for which they are praised appropriately. Most importantly, their achievements are now quantifiable

The NAs and CGs have become more aware than previously of the comprehensiveness and importance of maintaining patient abilities. Their attitudes toward their patients and their job changed as they become more involved in restoring patient abilities. In fact, they feel that they are actually the leading part of the team when it comes to improving patient functionality. 'They are enthusiastic, wants [sic] to lead the team and doing very well. They are definitely more alert and aware of what the patients can do and cannot do. They really know their patients from A-Z. ... it is wonderful!'. This indicated the BETA's usefulness with regard to managing the patient-carer interface.

An interesting secondary observation of the RNs was that they can use the BETA to make an assessment of the CGs' performance. There was consensus that if a CG has problems in scoring a patient on the BETA scale, it is because they do not have the intuitive awareness to assess a patient, or do not show enough interest to observe their patient's ability, or cannot function as a CG. A review of the BETA scores immediately shows who is capable of doing the work and who is not. 'We can score our care-givers [according to their competency as a carer] according to their scoring ability'. This points to the usefulness of the BETA with regard to managing quality care.

The final findings were that the BETA scale can be embedded into the nursing process as a routine nursing measure. 'It is working very well with us. If it can work here it can work anywhere else'. The care plan and the scoring are integrated into one process, so that what done does every day, one scores every day. Recording the correct score makes all the difference. It is a very positive experience, although it requires control from the nursing manager and the RNs to support and guide the NAs and CGs during the first few months. The daily scoring and recording makes a great difference as it helps them to verify their scores continuously as they go about their daily patient care routine. During the first few months all scores were achieved informally through consensus discussions amongst the RNs, NAs and CGs. The RNs reported that: 'it was very encouraging to witness the caregivers' enthusiasm to learn more about scoring and improving patient functioning'.

\section{Results from the Caregiver focus group}

Caregivers claim that the introduction of the BETA scale changed their perception of their scope of work. Previously, they believed it was their task to do everything for the patient, even if the patients were capable of doing basic tasks for themselves. Feeding patients that could eat themselves was considered to be one of the routine tasks of the CG. 'Spoiling patients by doing everything for them' was considered to be excellence in caregiving. 'Before, what was on our minds was that it was our job to do everything for our patients, even if they can do it for themselves, we must do it for them. In our minds that was our job'. 'This is how we were taught as caregivers to look after our patients ... to do everything for them' As a result, patients became increasingly dependent, demanding and abusive as their feelings of helplessness mounted. This made the task of the CG very difficult and tiring as there was no change for the better; it only got worse every day. As a result, they reported that their 'patients were getting quieter and even stopped talking, socialising, eating, walking'. In this environment, the CGs reported a feeling of not being in control of the situation, becoming either emotionally involved or detached, and also being physically tired and having aching backs from constantly lifting and transferring people. 'The job was hard before'.

However, with the introduction of the BETA scores on patient ability, the CGs reported having developed a new mindset with regard to the concept of caregiving. Initially, they experienced the training and implementation as being contradictory to their job description, which is highly task orientated. To make this change they needed continuous reconfirmation from their nursing superiors. It was also difficult to establish a BETA score whilst working and to apply one's mind at the same time to find a method, strategy or technique of how to improve the patient's independence. The changes to move away from the usual daily task tick list (feeds, bed baths, transfers, grooming, dressings, etc.) toward a patient outcomes score sheet of how much the patients can do for themselves, was also a daunting challenge. For continual confirmation and support, CGs required strong nursing supervision and constant reassurance. However, they reported a smooth transition within two weeks from a task-driven process to a patient-outcomes mindset.

'I think if you do something to somebody that can do it for him or herself, I think you are not giving better care'. This excerpt from the CG group's stated experienced sums up the new awareness that became prevalent amongst the CGs within a month of using the BETA. They mentioned this new mindset repeatedly as being the conceptual framework for their new approach to caring for their patients. They are also confident that the BETA has improved substantially the quality of their care to patients. They can now quantify the quality of their care by means of their patients' improved BETA scores. Moreover, they also confirmed improvements in patients that they never thought possible, such as: 'we see many (improved) changes in our patients'; '[they are] getting better, better really'; 'yes, our patients are getting more independent now'; 'also their memory is improving and they are expressing better'; 'there is a lot of improvement'.

Previously, the CGs thought their patients' ongoing decline was irreversible, but now they have discovered a restorative 
remedy that they have control over and this empowers them. The participants felt they have gained a lot of experience in a short period and they are enjoying their job more than before. With patients now making some physical effort with some of the CGs' more strenuous tasks, such as the transfers, the CGs also experienced less back injuries.

Finally, there is strong evidence that the BETA scores are successful in creating a universal language amongst nurses and CGs. In fact, the CGs mentioned that during the first months, they discussed patient scores during 'lunch time, tea time and even went to bed with scores'. They also created sessions as a group amongst themselves to discuss scores, as well as work sessions to score difficult patients. Furthermore, they initiated discussions on restorative techniques to increase their patients' scores. The scores were also discussed with the nursing staff and any changes were reported to the $\mathrm{RN}$ on duty.

\section{Discussion}

South African nurses working in rehabilitation, convalescent, gerontology and long-term care facilities where patients present with functional disabilities are at a disadvantage as they lack measurement tools to establish their patients' level of disability. As a result they are not capable of establishing empirically whether or not their patients are benefitting from their care. Moreover, without a measure to provide empirical evidence of a patient's functional gains, the nurse is at a loss when it comes to understanding the emerging science of restorative nursing. This study is the first of several that will contribute to the emergence of a restorative nursing science in South Africa.

The introduction of the BETA nursing scale into the specialised fields of rehabilitation, convalescence and gerontology nursing seems to be a watershed. There is evidence that NAs and CGs who perform $90 \%$ of the functional support at the patient-caregiver interface (Resnick 2004) have now discovered that their primary task is not to do every task for the patient, but to score and assess the patient's functional ability and find ways and means to improve the previous score. This was explained in the caregiver data as follows: 'I think if you do something to somebody that can do it for him or herself, I think you are not giving better care'.

The results revealed that the BETA scale has changed the nursing task into a nursing challenge with a patient-evidencebased outcome. The BETA scale has helped them to change their monotonous and laborious task-directed approach into personal challenges and achievements. The results further infer that the ultimate winners are the patients, who are able to regain their independence. The RNs reported that their role of task master has also changed into that of a coach with regard to restorative nursing practices. This has improved the quality of the nursing process significantly.

When it is taken into consideration that no training or information was given on restorative nursing techniques and outcomes, it is interesting to note that the CGs discovered by themselves that they ought to change the focus of their scope of work from task-orientated care to restorative care to achieve both patient and CG satisfaction. More interesting was the finding that their supervising RNs are not resisting this change, but rather following it with interest and anticipation.

\section{Limitations}

The only limitation of the study was the low numbers of nurses and primary carers available to participate in the focus groups, a common pragmatic phenomenon confirmed by McLafferty (2004). However, the limitation was overcome by prolonged engagement until data saturation was achieved. Furthermore, experienced, skilled and expert RNs, NAs, and CGs in the phenomenon under investigation participated in the study so as to provide rich and quality data (Kritzinger 1996; Morgan 1996; Twinn 1998). Finally, McLafferty's (2004) advice was followed to increase the quality of the data by allowing respondents with similar characteristics to participate in the same homogenous focus group, for example, RNs together and CGs together. This technique allowed for specificity and relevance and there was therefore a low risk of having to verify the data collected.

\section{Recommendations}

The most important recommendation is to do a follow-up study to determine the BETA scale's construct validity.

Future in-service and formal education programmes should include training in the use of the BETA by RNs, NAs and CGs working in the field of restorative nursing. They should also include the revision of care plan methods and techniques so as to assist NAs and CGs with regard to advancing their patients' BETA scores. Programmes will be required for RNs to allow them to implement the restorative nursing process and to manage it effectively.

The change from curative practice to restorative practice is a necessary mind shift that many nurses may find difficult. However, this study revealed that the BETA is an important tool for facilitation of this process.

\section{Conclusion}

Strong implicit and explicit evidence supported the BETA scale's nursing utility; it has made RNs, NAs and CGs aware of the value of having the ADLs embedded in the restorative care process. This new awareness was manifested explicitly in the ease with which the NAs and CGs recognised, observed and expressed the BETA scores in their daily routine. Implicitly, they have become aware that improvement in BETA scores has a direct correlation with improvement in the patient's independence and resultant wellbeing. Thus, as RNs, NAs and CGs became aware that restoration of patient independence is their core focus, they actively explored techniques of increasing patients' BETA scores. Through this process the NAs and CGs also became aware of the fact that they are in control of nursing effectiveness and efficiencies. 
The BETA was developed by South African nurses for South African nurses and CGs to allow them to render better care for patients requiring functional gain. The nursing participants in this study were very receptive when it came to developing and applying the BETA. There was much enthusiasm with regard to exploring a new nursing science that was clearly lacking in the field.

\section{Acknowledgements}

The authors would like to acknowledge the many nurses that participated voluntarily in the study and also their colleagues from the School of Therapeutic Sciences at the University of Witwatersrand for their support as peer reviewers in the study.

\section{Competing interests}

The South African Database for Functional Measures (Pty) Ltd provided financial support for this study. Although the SADFM gave written permission to publish this article, and although the copyrights of this article vest with the publishers, the patent rights for the BETA belong to SADFM (RSA patent registration number 2008/09086).

\section{Authors' contributions}

This article was based on the primary research performed by H.J.L. (South African Database for Functional Medicine) under the supervision of J.C.B. (School of Therapeutic Sciences, University of the Witwatersrand) and D.C. (Department of Occupational Therapy, University of the Witwatersrand) for the $\mathrm{PhD}$ thesis, 'The validation of nursing measures for patients with unpredictable outcomes'. The draft was formulated by H.J.L. and J.C.B. and D.C. contributed to the finalisation of the article.

\section{References}

Barbara, A. \& Whiteford, G., 2005, 'Clinical utility of the Handicap Assessment and Resource Tool: an investigation of its use with the aged people in hospital', Australian Occupational Therapy Journal 52(1), 17-25. http://dx.doi.org/10.1111/ Australian Occupational Thera

Bond, T.G. \& Fox, C.M., 2007, Applying the Rasch Model: Fundamental Measurement in the Human Sciences, Lawrence Erlbaum Associates, Mahwah, NJ.

Foxcroft, C.D., Patterson, H., Le Roux, N. \& Herbst, D., 2004, 'Psychological assessment in South Africa: a needs analysis: the test use patterns and needs of psychological assessment practitioners: final report', July edition, viewed 25 May 2013, from http://www.hsrc.ac.za/en/research-outputs/view/1642
Heinemann, A.W., Kirk, P., Hastie, B.A., Semik, P., Hamiliton, B.B. \& Linacre, J.M. 1997, 'Relationships between disability measures and nursing effort during rehabilitation for patients with traumatic brain and spinal cord injury', Archives of rehabilitation for patients with traumatic brain and spinal cord injury', Archives of
Physical Medicine and Rehabilitation 78(2), 143-149. http://dx.doi.org/10.1016/ S0003-9993(97)90255-0

Hsieh, H. \& Shannon, S., 2005, 'Three approaches to qualitative content analysis', Qualitative Health Research Journal 15(9), 1277-1288. http://dx.doi org/10.1177/ 1049732305276687, PMid:16204405

Kritzinger, J. 1996, 'Introducing Focus Groups', in N. Mays \& C. Pope (eds.), Qualitative Research in Health Care, pp. 36-45, B.M.J. Publishing Group, London.

Lang, T.A., Hodge, M., Olsen, V., Romano, P.S. \& Kravits, R., 2004, 'Nurse-patient ratios: a systematic review on the effects of nurse staffing on patient, nurse employee, and hospital outcomes', Journal of Nursing Administration 34(7-8), 326-337. http://dx.doi.org/10.1097/00005110-200407000-00005, PMid:15303051

Lobelo, M.I., 2004, 'Experiences of relapsed psychiatric patients in Mafeking in the North West Province', MCur Thesis, Department of Nursing Sciences, Rand Afrikaans University, Johannesburg.

Loubser, HJ., 2012, 'The validation of nursing measures for patients with unpredictable outcomes', PhD Thesis, Department of Nursing Sciences, Witwatersrand University, Johannesburg.

Lundgren-Nilsson, A., 2006, 'Characteristics of the Functional Independence Measure in patients with neurological disorders' PhD Thesis, Department of Clinical Neurosciences, Gotenborg University, Sweden.

Mantle, J. \& Funke-Furber, J., 2003, In dialogue with Verah Mclver - The Forgotten Revolution: the Priority Method: a restorative care model for older persons, Trafford, Victoria, Canada.

McGillis-Hall, L., Doran, D., Baker, G.R., Pink, G.H., Sidani, S. \& O’Brien-Pallas, L., 2001, 'A study of the impact of nursing staff mix models and organisational change strategies on patient, system and nurse outcomes', University of Toronto, Toronto, Canada, viewed 20 April 2009, from fhs.mcmaster.ca/nru/old\%20nru/ documents/web.McGillis\%2OHall.pdf

McLafferty, I., 2004, 'Focus group interviews as a data collecting strategy', Journal of Advance Nursing 48(2), 187-194. http://dx.doi.org/10.1111/j.13652648.2004.03186.x, PMid:15369499

Morgan, D., 1996, 'Focus groups', Annual Review Sociology 22, 129-152. http://dx.doi. org/10.1146/annurev.soc.22.1.129

Nelson, A., Faan, R.N., Powell-Cope, G., Palacios, P., Luther, S.L., Black, T., et al. 2007 , 'Nurse staffing and patient outcomes in inpatient rehabilitation settings', Rehabilitation Nursing 32(5), 179-202. http://dx.doi.org/10.1002/ j.2048Rehabilitation Nursing 32(5), $179-202$
7940.2007.tb00173.x, PMid:17899990

Nilsson, A.L., Sunnerhagen, K.S. \& Grimby, G., 2005, 'Scoring alternatives for FIM in neurological disorders applying Rasch analysis', Acta Neurological Scandinavica
$111(4), 264-273$.
http://dx.doi.org/10.1111/j.1600-0404.2005.00404.x, $111(4), \quad 264-273$
PMid:15740579

Resnick, B., 2004, Implementing restorative care nursing in all settings, Springer Publishing Company, New York.

Resnick, B., Cayo, J. \& Pretzer-Aboff, I., 2009, 'Implementation of the 6-week educational component in the Res-Care Intervention: process and outcomes', Journal of Continuous Education in Nursing 40(8), 353-360. http://dx.doi. org/10.3928/00220124-20090723-04, PMid:19681572

Stevens, S.S., 1946, 'On the theory of scales and measurements', Science 103(2684), 677-680. http://dx.doi.org/10.1126/science.103.2684.677, PMid:17750512

Toomey, M., Nicholson, D. \& Carswell, A., 1995, 'The clinical utility of the Canadian Occupational Performance Measure', Canadian Journal of Occupational Therapy 62(5), 242-249. http://dx.doi.org/10.1177/000841749506200503

Twinn, S., 1998, 'An analysis of the effectiveness of focus groups as a method of qualitative data collection with Chinese populations in nursing research' Journal of Advanced Nursing 28(3), 654-661. http://dx.doi.org/10.1046/j.13652648.1998.00708.x, PMid:9756235

World Health Organization, 1980, International classification of impairments, disabilities, and handicaps; a manual of classification relating to the consequences of disease', World Health Organization, Geneva, viewed 12 February 2012 from http://www.who.int/topics/disabilities/en/ 